Revista lus et Praxis, Año 20, No 1, 2014, pp. 253 - 276

ISSN 0717 - 2877

Universidad de Talca - Facultad de Ciencias Jurídicas y Sociales

"El concepto 'especial' en el Código Civil: diferencias de significación entre el artículo $4^{\circ}$ y el artículo 13"

Edison Carrasco Jiménez

Trabajo recibido el 12 de agosto y aprobado el 2 de diciembre de 2013

\title{
El concepto "especial" en el Código Civil: diferencias de significación entre el artículo $4^{\circ}$ y el artículo 13 THE CONCEPT "SPECIAL" IN THE CIVIL CODE: DIFFERENCES BETWEEN MEANINGS OF ARTICLES $4^{\circ}$ AND 13
}

\author{
EdisOn CARRASCO JimÉneZ*
}

\begin{abstract}
RESUMEN
El presente artículo tiene por finalidad revisar el concepto de "especial" en el Código Civil chileno y específicamente en los arts. $4^{\circ}$ y 13 del mismo cuerpo legal, de acuerdo a los términos utilizados por el legislador civil. Se polemiza respecto de la interpretación casi unánime de la doctrina acerca del art. $4^{\circ}$, en orden a que éste consagraría el concepto de especialidad en el sentido del llamado por la filosofía del derecho "criterio de especialidad" para resolver la oposición entre leyes generales y especiales, criterio que sí consagraría el art. 13 del Código Civil. Siendo así, el término "especiales" del art. 4, apunta más bien al concepto de especialización o de leyes especializadas. Ello implica que los términos "especial" o "especiales", usados en la legislación común, aluden a más de un significado, existiendo una polisemia de los términos antes expresados.
\end{abstract}

\section{ABSTRACT}

The present article has the sole aim of summarizing the special concept in the Chilean Civil Code, and in particular arts. $4^{\circ}$ and 13 of the aforementioned body, in accordance with the terms utilized by the civil legislator. Said article refers to the almost unanimous interpretation of the doctrine relating to art. $4^{\circ}$, in order that the concept of specialty may be enshrined, in the sense of the socalled philosophy "criterion of speciality" to resolve the opposition between general and special laws, criterion that is to be enshrined in art. 13 of the Civil Code. In this way, the term "special" of art. $4^{\circ}$, relates rather to the concept of specialization or to specialized laws. The article infers that the term "special" used in common legislation, points to more than one effect, in the event of ambiguity relating to the aforementioned terms.

$$
\begin{gathered}
\text { Palabras CLave } \\
\text { Concepto de "especial", Art. } 4^{\circ} \text { Código Civil, Art. } 13 \text { Código Civil, } \\
\text { Criterio de especialidad } \\
\text { KerwOrDS } \\
\text { Concept of "special", Art. } 4^{\circ} \text { Civil Code (Civil Law), Art. } 13 \text { Civil Code (Civil Law), } \\
\text { Criterion of specialty }
\end{gathered}
$$

\footnotetext{
* Investigador CTIT (Centro Telúrico de Investigaciones Teóricas). Abogado Asesor División de Estudios, Evaluación, Control y Desarrollo de la Gestión, Fiscalía Nacional de Chile. Doctor @ Derecho Penal, Universidad Salamanca, España. Correo electrónico: ecarrasj@hotmail.com.

Las opiniones vertidas por el autor no representan necesariamente el pensamiento de la Fiscalía Nacional de Chile.
} 


\section{Exposición}

La interpretación canónica de los arts. $4^{\circ}$ y 13 del Código Civil, que son los que revisaremos en todo el cuerpo del presente artículo, responde a un significado preciso en torno a los términos "especiales", "particulares/generales" empleados en ambos artículos, que aluden a un concepto de especial determinado y que correspondería al criterio de la especialidad descrito por la Filosofía del Derecho, referido a las relaciones existentes entre ley general y ley especial, y que tiene su consecuencia hermenéutica en la aplicación de la regla lex specialis derogat legi generali.

Sin embargo, entendemos que existe una errada interpretación del art. $4^{\circ}$ en específico, que hace a la doctrina homologarlo al art. 13, el cual sí consagraría la especialidad. Lejos de ello, el art. $4^{\circ}$ no prescribe especialidad alguna, ya que el término "especiales" que recoge su texto, no alude semánticamente al concepto de especialidad antes señalado, sino más bien al de especialización, esto es, dedicación a una materia en específico que por su particularidad se parcela para ser regulada con mayor precisión.

Para la fundamentación de lo ya expresado, y en tanto constituye la hipótesis de trabajo, se hará uso de un procedimiento de desambiguación basado en el examen dogmático-jurídico, en el estudio de fuentes y de los análisis que se aportan desde la Filosofía del Derecho, con el fin de establecer demarcaciones metodológicas en los conceptos.

\section{El concepto "especial" inferido dogmáticamente: arts. $4^{\circ}$ y 13 del Código Civil}

En la Ley chilena -hasta donde sabemos-, no existe una definición de los términos "especial", "especiales", "particulares"/"generales". A este respecto, entonces, habría de hacerse aplicación de la regla de interpretación del Código Civil del art. 20 sobre el significado legal y el natural y obvio, cuya regla contempla dos consecuencias hermenéuticas; una positiva, según la cual la palabra se entenderá en su sentido natural y obvio; otra negativa, que supone no tomar la palabra en sentido legal alguno.

Ello implica que una palabra que constituye un concepto, al no disponer de definición legal, se abre semánticamente a las posibilidades del sentido natural y obvio, y clausura una significación legal para la misma.

Pero ello no implica que la ley no utilice significativamente un concepto con características definidas según el contexto en que se expresa. Por lo cual lo que se clausura es un significado expreso y unívoco de la ley (en razón del principio de legalidad), pero no niega que, entendiéndose un concepto en un sentido natural y obvio, éste posea un sentido multívoco, y por ende, polisémico. 
Las referencias a un concepto de especial se pueden inferir de la expresión "demás especiales" que el art. $4^{\circ}$ del Código Civil incluye en su texto, y que eventualmente podrían ser generalizadas, sobre la base del carácter común, general e introductorio del Código Civil, a toda la legislación chilena ${ }^{1}$. Lo mismo ocurre con el binomio de términos "particular"/ "general" del art. 13 del referido cuerpo legal.

Pasaremos a revisarlos y tratar de determinar su significado, en uno y otro caso.

\section{El art. 13 del Código Civil y sus significados}

\section{a) Análisis histórico y gramatical de la disposición}

El art. 13 del Código Civil señala: "Las disposiciones de una ley, relativas a cosas o negocios particulares, prevalecerán sobre las disposiciones generales de la misma ley, cuando entre las unas y las otras hubiere oposición"

En la explicación que Bello entrega en una nota al art. 13, hace referencia a la regla in toto jure generi per speciem derogatur ${ }^{2}$, expresada en el Digesto por Papiniano y cuya fórmula completa es in toto jure generi per speciem derogatur, et illud potissimum habetur, quod ad speciem directum est ${ }^{3}$ [en todo el derecho el género es derogado por la especie, y se considera principalmente lo que se refiere á (sic) la especie] $]^{4}$.

Esta cláusula papiniana, en tanto reducida a regla, es conocida normalmente como regla de especialidad ${ }^{5}$ (directamente derivada de la inferencia

\footnotetext{
1 "Este título debe considerarse como una introducción, no sólo al presente Código Civil, sino a la legislación toda. Cualquiera, por ejemplo, que sea la ley que se trate de interpretar, ya pertenezca al presente Código, ya a los códigos que sucesivamente se publiquen (...) es preciso observar en su interpretación las reglas contenidas en el párrafo $4^{\circ}$ de este Título Preliminar" (Bello (1981), nota de Bello, p. 25).

2 BeLlo (1981), p. 38.

3 D. $50,17,80$.

4 En el Digesto hay otras referencias que van justamente en el sentido de la regla de especialidad. Así por ejemplo, el mismo Papiniano quien lo refiere al área delictual: "Sanctio legum quae novissime certam poenam generaliter irrogat his, qui legis praeceptis nos obtemperaverit, ad eas species pertinere non videtur quibus ipsa lege poena specialiter addita est. Nec ambigitur in cetero omni iure speciem generi derogare, nec sane verisimile est delictum unum eadem lege variis aestimationibus coerceri" (D.48, 19,41). Igualmente en un comentario de Ulpiano a Sabino en lo concerniente a los hijos: Lex naturae haec est, ut qui nascitur sine legitimo matrimonio, matrem sequatur, nisi lex specialis aliud inducit ["a ley de la naturaleza es esta, que el que nace fuera de legitimo matrimonio, siga á [sic] la, madre, salvo si una ley especial determina otra cosa"] $(D .1,5,24)$. Esto lo relaciona Biondi igualmente con la referencia de Ulpiano: "la derogación se califica como lex specialis respecto del ius naturale, que en el parágrafo allí citado se califica expresamente como ius commune" (D.1, 1,6). Véase BıONDI (1951), p. 16.

5 BobBio (1987), p. 195, p. 203; GuAStinI (1999), pp. 437-450, p. 441.
} 
clásica de género a especie de Aristóteles), y para hacer referencia a su estudio aquí, la denominaremos como criterio o regla de especialidad, o simplemente especialidad.

Esta regla es entendida como una "meta-norma" (aunque podría ser también una meta-regla ${ }^{6}$ ) que, como tal, cuenta como suerte de "norma" (regla) que resuelve los problemas presentados entre normas (norma referida a normas) ${ }^{7}$. Y tales normas a las que se aplica dicho criterio, han de considerarse previamente como normas especiales y normas generales ${ }^{8}$.

Tal regla de especialidad es aceptada por la unanimidad de la doctrina para el art. 13 del Código Civil ${ }^{9}$, y es posible visualizarla en la Historia de la Ley, de los modos siguientes:

- El Proyecto de 1853 en relación al contenido del art. 13, en primer lugar, hablaba de "leyes especiales" y "leyes generales", no de disposiciones, como el art. 13 actual lo consagra. Pero Bello modifica, desde el Proyecto de 1853 al Código Civil, la palabra "leyes" por "disposiciones". Este cambio es interesante, porque parece indicar que Bello entiende la palabra "ley" en el Proyecto de 1853 en un sentido restringido, esto es, como sinónimo de disposición, y es así como parece aclararlo ya en la redacción definitiva del Código Civil. Siendo así, no es el corpus normativo el considerado como ley especial, sino las disposiciones que conforman dicho corpus ("Las disposiciones de una ley", art. 13). Desde ese punto de vista, solo así es posible entender la regla de la "ley especial deroga la ley general" [lex specialis derogat legi generali] consagrada, y la determinación del problema mediante el añadido textual al Código Civil "cuando entre las unas y las otras hubiere oposición". Aún más ni siquiera la oposición excluye toda la norma general incompatible, "sino -como señala Bobbio- solo aquella parte de la ley general que es

6 Zorzetto (2011), § 63. Disponible en: http://revus.revues.org/708 [visitado el 29/07/2013].

7 VisSer y Bench-Capon (1998), pp. 27-57, p. 38; FerRajoli (2006), p. 5.

${ }^{8}$ GuAstin define la norma especial del siguiente modo: "Pongamos que una norma N1 regule de un modo determinado una cierta clase de supuesto de hecho F ("si F, entonces $G^{\prime \prime}$ ). En hipótesis, la clase de supuesto de hecho F incluye diversas subclases: F1, F2, F3, etcétera. Entre la clase F y sus subclases, evidentemente existe una relación de "género" a "especie". Pongamos además que una segunda norma N2 regule en modo diverso una de estas subclases, por ejemplo F2 ("Si F2, entonces no-G). De esta forma la norma N2 excluye del campo de aplicación de la norma N1 a la subclase del supuesto de hecho F2, y por tanto lo restringe. Ahora bien, en estos casos, se suele decir indiferentemente que N2 constituye una norma "especial" respecto a N1, que N2 es una "excepción" a N1, o que N2 "deroga" a N1" (GuASTINI (1999), p. 441).

9 Por todos, Claro (1978), No 61, p. 37; Borja (1901), p. 69; Guzmán (2007), pp. 152 y ss.; Alessandri et al. (1998), p. 51; Vodanovic (2001), p. 21; Otárola (2012), pp. 89-108, en especial p. 93; Orellana Retamales (2000), pp. 807-822, pp. 817 y ss.; Ruz (2011), p. 133; Vergara (2010), pp. 31 y ss. 
incompatible con la ley especial"10. Ello porque para la aplicación del caso en concreto, será la disposición que regule especialmente la materia que se prefiere o "prevalece" 11 , ante la general que queda, por ende, excluida de la aplicación, que es finalmente el significado semántico de la anterior fórmula con la palabra "deroga". Dicha exclusión, según Bobbio, significa que "la ley general pierde vigencia parcialmente (...) la lex specialis, de dos normas incompatibles, la una general y la otra especial (o excepcional), prevalece la segunda: lex specialis derogat generalis (...) deroga una ley más general, o sea que substrae de una norma una parte de la materia para someterla a una reglamentación diversa..." [resaltado del autor] ${ }^{12}$, con lo que se entiende derogada para el caso en específico ${ }^{13}$.

- El Proyecto de 1853, respecto de este artículo 13, contenía la referencia "leyes generales que parecen extenderse a la misma cosa o negocio"14. Esta referencia fue eliminada ya para el Código Civil de 1855 y en su redacción definitiva. Obvio es que haya sido eliminada, cuando el art. 13 hace referencia a "disposiciones de una ley, relativas a cosas o negocios particulares" y "disposiciones generales", con lo cual produce ya el contraluz entre disposiciones especiales y generales. Dicho contraluz es entendido por el art. 13 como especialidad, por la forma de la redacción de dicho artículo, el cual hace prevalecer disposiciones particulares sobre las generales, existiendo oposición entre ellas, es decir, las formas de razonamiento y consecuencias lógicas típicas que se presenten en la regla de especialidad. Por ende, era más o menos claro que su conservación no se apreciaba como necesaria en la redacción definitiva del Código. Sin embargo, esta expresión eliminada reafirma aún más el concepto de especial inferido del tenor del artículo, ya que si hace mención de las cosas o negocios, ha de apuntar a que mientras las disposiciones de una ley tratan una cosa o negocio particular, las disposiciones de la ley general se refieren a la misma cosa o negocio, pero que la primera la trata de modo particular. Esto quiere decir que es la misma área de regulación entre ambas disposiciones de ley.

- En expresiones tales como "disposiciones de una ley, relativas a cosas o negocios particulares" del texto del art. 13, es posible inferir la especialidad, y además, entre dicha frase y su contraluz con la cláusula "disposiciones ge-

\footnotetext{
${ }^{10}$ ВоввІо (1987), р. 195.

${ }^{11}$ BobBIO (1987), p. 195. Y que de hecho Kantorowicz define la sentencia como lex specialis en relación a la ley. Kantorowicz (1949), pp. 325-373, p. 364.

12 Воввіо (1987), р. 195.

${ }_{13}$ PINO (2012), p. 26.

${ }^{14}$ BelLo (1981), p. 38. La disposición completa reza: "Las leyes especiales relativas a una cosa o negocio particular, prevalecerán sobre las leyes generales que parecen extenderse a la misma cosa o negocio".
} 
nerales" a las que se refiere el artículo de forma expresa. En efecto, y como veníamos diciendo, las cosas o negocios particulares son las materias de las que trata la disposición. El ser "particulares" denota la diferenciación con las "disposiciones generales", y como la primera conserva los elementos de la segunda pero de modo más detallado al caso que expone la disposición especial, ésta es la razón jurídica por la que prima. Pero esta razón jurídica está expresada fundamentalmente en la frase "cuando entre las unas y las otras hubiere oposición", lo que implica el problema de aplicación a un caso concreto, y donde dos disposiciones concurren en forma opuesta. El elemento diferenciador que contiene la disposición especial, por ser particular en la regulación del negocio o materia, prima para ser ésta quien regule el caso. Por ende, de no existir oposición jurídica, dicha prevalencia no existiría.

En consecuencia, y según el art. 13 del Código Civil, el fenómeno que describe para las disposiciones especiales, de un modo unívoco y copulativo, ocurre:

- $\mathrm{Si}$, y solo si se produce entre disposiciones legales.

- $\mathrm{Si}$, y solo si se produce entre las disposiciones de una misma ley.

- $\mathrm{Si}$, y solo si existe oposición entre las disposiciones de una misma ley.

La nota de BeLLo, relativa al art. 13, señala al respecto lo siguiente:

"La oposición debe aparecer en una misma ley, para que haya lugar a lo que en este artículo se dispone: la regla no sería segura, si la oposición resultase de la comparación de una ley con otra distinta. Todos los artículos de un código, y aun de distintos códigos, coordinados entre sí, como, por ejemplo, los códigos franceses civil, comercial y de enjuiciamiento, constituyen una misma ley"15.

Dicha nota marca varias cosas significativas:

- Solo existe la especialidad del art. 13 cuando las disposiciones generales y especiales aparecen en una misma ley, con lo cual la historia del art. 13 coincide con lo que del solo tenor literal es inferido.

- No es que la especialidad como fenómeno jurídico no pueda aplicarse a disposiciones de leyes distintas, solo que la aplicación de aquélla en dicha situación no es segura. Ello implicaría la existencia de dos clases de aplicación de la regla, criterio o principio de especialidad, y a su vez, dos clases de consecuencias correlativas: a) en disposiciones de la misma ley: alta probabilidad de certeza en el resultado hermenéutico; b) en disposiciones de leyes distintas: baja probabilidad de certeza en el resultado hermenéutico.

Para entender el concepto de ley que se señala, nos remitimos al propio Código Civil. Es así como existe un concepto de ley particularísimo del art. 13 y diferente al concepto de ley del art. $1^{\circ}$ del mismo Código. Dicho concepto,

${ }^{15}$ Bello (1981), p. 38. 
para fundar su significado, se basa en las relaciones normativas existentes entre las disposiciones y el corpus normativo. Así, ley sería aquella en que las disposiciones se encuentran formando parte de su corpus ("todos los artículos de un código"). Pero también son ley las disposiciones de distintos corpus normativos "coordinados entre sí". Toma como referencia los Códigos Civil, de Comercio y de Enjuiciamiento francés, que por período, habrían de remitirnos a los Ilamados "napoleónicos". Siendo así, y en virtud de la génesis de aquellos y su contexto, la expresión "coordinados entre sí", puede tomarse en el sentido de unidad sistemática y de finalidad, que sería consecuencia del mismo prisma (como forma de "plasmar en la legislación los resultados políticos de la Revolución francesa" y la personalidad de Napoleón ${ }^{16}$ ), mismo régimen político, fechas de publicación cercanas (civil 1804, comercio 1807, enjuiciamiento civil 1806), inspirados bajo los mismos delineamientos liberales ${ }^{17}$, resultados todos del proceso de codificación ${ }^{18}$, considerados como códigos modernos ${ }^{19}$, lo que además, y demostrando dicha unidad armónica, hace llamarlos, junto con el penal y de instrucción criminal, como los "cinco Códigos" ${ }^{\prime 20}$.

Siguiendo lo anterior, estimamos que la coordinación a que alude Bello se refiere a una unidad sistemática y de objetivos, y a una unidad ideológica. Si este fuera el caso, entonces disposiciones de leyes distintas podrían ser consideradas como de alta probabilidad de certeza en el resultado hermenéutico de la regla, criterio o principio de especialidad, pero siempre entre disposiciones y no entre leyes completas, entendidas como corpus normativo.

\section{b) Observaciones desde la filosofía del derecho acerca de la especialidad}

Se hace necesario establecer un parangón entre lo que la Filosofía del Derecho ha precisado para la especialidad (regla o criterio de especialidad) y el art. 13 en comento.

Ross señala a las inconsistencias entre dos normas como uno de los problemas lógicos de interpretación, que ocurren "cuando se imputan efectos jurídicos

\footnotetext{
${ }^{16}$ RADBRUCH (2005), p. 74.

17 Ver VAn RHeE (2011), pp. 19-20.

${ }^{18}$ Es este mismo objetivo lo que, e inspirado en este proceso napoleónico de codificación, lo que hace expresar la Constitución gaditana de 1812 que "el Código civil y el criminal y el de comercio serán unos mismos para toda la Monarquía..." (BARÓ (1993), p. 53).

${ }^{19}$ A pesar de la crítica al Código procesal civil francés, no se deja de señalarlo como moderno. Ver VAN RHee (2011), p. 19.

${ }^{20}$ RadBruch (2005), p. 74.
} 
incompatibles a las mismas condiciones fácticas ${ }^{\prime 21}$. Así, la especialidad sería la forma de solución interpretativa de la "inconsistencia total-parcial":

"esto es, cuando una de las dos normas no puede ser aplicada bajo ninguna circunstancia sin entrar en conflicto con la otra, mientras que ésta tiene un campo adicional de aplicación en el cual no entra en conflicto con la primera. Tal inconsistencia se da cuando un círculo se encuentra dentro del otro (...) Las expresiones "regla general" y "regla particular" son correlativas. Una regla es particular en relación a otra si su hecho condicionante es un caso particular del hecho condicionante de la otra regla. Si el hecho condicionante de la última es $\mathrm{H}(\mathrm{a}, \mathrm{b}, \mathrm{c})$, esto es, un hecho definido por las notas a, b, c, entonces el hecho condicionante de la regla particular $\mathrm{H}(\mathrm{a}, \mathrm{b}, \mathrm{c}, \mathrm{m}, \mathrm{n})^{\prime \prime 22}$.

La idea gráfica de Ross de los círculos concéntricos busca figurar cómo la norma especial es parte de la primera, con contener el supuesto mayor, respecto del cual la norma especial establece particularidades que hacen que sea ésta la que se aplique y no la que contiene el supuesto mayor.

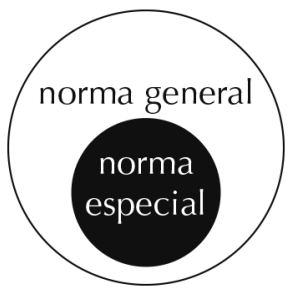

Ello no es diferente a lo planteado por lo que se infiere del art. 13, ya que según éste, el elemento que define la razón jurídica es la oposición entre disposiciones, que concuerda con el hecho de que "una de las dos normas no puede ser aplicada bajo ninguna circunstancia sin entrar en conflicto con la otra"23; el hecho de que la disposición contenga o se refiera a cosas o negocios particulares no es diverso del hecho de contener una disposición "un campo adicional de aplicación en el cual no entra en conflicto" con la disposición general ${ }^{24}$. Es lo que puede expresarse del siguiente modo:

\footnotetext{
${ }^{21}$ Ross (1974), pp. 124-125.

22 Ross (1974), p. 124.

${ }^{23}$ Ross (1974), p. 124.

${ }^{24}$ Ross (1974), p. 124.
} 




Ahora, lo dicho acerca de la alta probabilidad y baja probabilidad respecto de que el art. 13 establezca la especialidad en disposiciones de un mismo o diferente cuerpo normativo que hicimos mención más atrás, se relaciona mucho con lo que señala Guastını.

El autor expresa que existen dos situaciones donde operaría el criterio de especialidad; la primera, en que la norma general y la especial se encuentran en un mismo "documento normativo"; la segunda, en que la norma general y la especial se encuentran en diferentes documentos normativos ${ }^{25}$. El primer caso sería un concurso aparente, ya que la norma especial siempre sería eficaz en este caso, ante una norma general que la pierde a favor de aquélla, donde de subsistir la norma general la especial no tiene ningún efecto y nunca encontraría aplicación. Diferente es el segundo caso -que sería un concurso real-, donde una de las normas puede ser ineficaz. Pero esto último no puede resolverse por el criterio de la especialidad por sí mismo, sino en relación a los otros criterios, como el jerárquico y el cronológico ${ }^{26}$.

\footnotetext{
${ }^{25}$ Guastini (1999), p. 442.

${ }^{26}$ GuAstini (1999), pp. 442-443. En un sentido similar NinO señala que la aplicación de la regla de especialidad no soluciona de modo mecánico las contradicciones entre normas, ya que finalmente está sujeta a evaluaciones pragmáticas y donde los criterios jerárquicos y cronológicos concurren en situaciones particulares, sin existir de por medio normas que soluciones los conflictos entre diversas reglas (como cuando existen normas posteriores y anteriores y a la vez generales y especiales) (NINO (2003), pp. 275-276). El reconocimiento que hace NiNO, sin referirse al mismo cuerpo de la ley o en diferentes leyes, no es tan diferente al de GUASTINI, si el contexto desde el cual parte NinO, parece ser el de normas que se encuentran en cuerpos normativos distintos, porque si no, no hablaría de criterios como el jerárquico y el cronológico como elementos a considerar junto al de especialidad, para resolver en conjunto las inconsistencias o antinomias normativas En este marco es donde NINO reconoce que la especialidad como regla no es mecánica en su aplicación. De ahí que para el caso de la especialidad entre cuerpos normativos distintos, tenga lugar lo que se pregunta Bоввı ante la existencia de conflictos entre criterios que inevitablemente se añaden: " $i$ Existe un cuarto criterio que permite resolver las antinomias de este tipo? (...) Debemos responder que no" (Воввı (1987), p. 196). Por ello el autor señala que de cualquier modo la utilización de uno u otro criterio es entregada a la interpretación judicial (Bоввı (1987), pp. 189 y ss.; énfasis en el punto en PINO (1998), pp. 84-126,
} 
Justamente es este reconocimiento el que lleva a postular en la especialidad entre disposiciones de diferentes cuerpos normativos, en primer lugar, y ante la interpretación restrictiva que implicarían dos disposiciones general y "especial", ausencia de un criterio que determine cuándo una disposición es especial en relación a otra general, además de un criterio que determine cuándo aplicar dicha interpretación ${ }^{27}$; en segundo lugar, la ausencia de criterios objetivos in toto que eliminen el conflicto entre meta-normas, y a su vez, la búsqueda de formas de solución de las mismas ${ }^{28}$. No así para el caso de disposiciones especiales y generales que se encuentren en un mismo cuerpo normativo.

p. 21, o como señala MARINELLI, "a través de una evaluación que se hace sobre una base de caso por caso en función de la ratio legis y de los datos específicos del problema" (MARINELLI (1998), pp. 145-158, p. 156). Lo señalado por NıNO y BobBıo alude a la dificultad en la aplicación del criterio de especialidad cuando existen dos disposiciones en cuerpo normativos distintos, porque si fuere en un mismo cuerpo normativo, no tendrían razón de hablar de criterios jerárquicos o cronológicos, lo cual da a entender que son disposiciones en leyes distintas. Y ello es más que obvio: dos disposiciones de una misma ley responden a idéntica data cronológica y a idéntica jerarquía, por encontrarse en la misma ley. Al buscar un criterio de resolución de criterios (meta-metacriterio), supone inmediatamente la idea en ser leyes distintas. De cualquier modo, desde el derecho civil como la filosofía del derecho (incluso el mismo BоввіO), tratan de esbozar meta-reglas que resuelvan el conflicto. JOSSERAND, por ejemplo, señala dos principios: la primacía del criterio jerárquico y la inexistencia de incompatibilidad entre leyes generales y especiales (entendida éstas como cuerpo normativo, ver JOSSERAND (1952), p. 75 y de su contexto, e igualmente a su relación con p. 61: "Damos a dicha expresión [de Ley escrita] la acepción más amplia que puede recibir, haciéndole designar toda regla social obligatoria...".). En efecto, señala el autor: "La forma tácita que, resulta de la oposición, de la incompatibilidad entre dos disposiciones que se contradicen: siendo irrealizable su aplicación simultánea, es preciso elegir entre ellas, y la elección se habrá de ejercer naturalmente a favor de la más reciente, que se presume es la mejor; el pasado puede ser abolido por el porvenir, pero el fenómeno inverso sería inconcebible. Es de notar que la abrogación tácita no obra sino en la medida más estricta, es decir, en la de la contradicción entre ambos textos; la ley antigua subsiste en la medida en que no es contradicha por la ley nueva. Y por esa razón una ley general no abroga tácitamente una ley especial contraria más antigua, por no ser en modo alguno la existencia de una excepción incompatible con la de una regla: 'legi specialis per generalem nos derogaturr', o 'generalia specialibus nos derogant', mientras que a la inversa una ley especial más reciente abroga, en la medida de sus disposiciones, la ley general anterior, specialia generalibus derogant" [resaltado es del autor] (Josserand (1952), p. 75). Pero como puede notarse, la primacía de la ley especial en el segundo caso, no se produce por la especialidad, sino más bien por ser la Ley especial posterior a la Ley general. JOSSERAND a través del criterio cronológico y de la inexistencia de incompatibilidad entre ley especial y general, zanja cualquier colisión entre metanormativa. Bоввı resuelve del siguiente modo, entendiendo por conflicto $(\mathrm{C})$, por criterio jerárquico (j), por criterio cronológico (r) y por criterio de especialidad (e) lo que sigue: $\mathrm{Cjr}=\mathrm{j}$; Cje=j; Cer=e (Bоввı (1987), pp. 203-204). Ross para Cer=e aunque como probabilidad. "Más tarde -señala el autor- la primitiva regla general es reemplazada por otra que no menciona las excepciones. En tal situación para determinar si las excepciones anteriores pueden todavía ser consideradas válidas habrá que recurrir a otros datos y a consideraciones valorativas" (Ross (1974), p. 127); y para Cje=j (Ross (1974), pp. 127-128).

27 LASTRA (2003), pp. 1-16, pp. 10-11.

${ }^{28} \mathrm{Ni}$ aún tan claras en los conflictos constitucionales, por diferencias en la naturaleza de criterios, donde el jerárquico se entiende como deóntico en relación al carácter constitutivo de la especialidad y el cronológico (Ferrajol (2006), p. 5), y aun donde el Tribunal Constitucional en Italia no aplica la 
Esta es la posibilidad en la que se enmarcaría el art. 13, y por ello la alta probabilidad de la especialidad de acuerdo a la situación fáctico-normativa planteada por dicha disposición, ya que siempre ante la existencia de una disposición normativa especial en un mismo cuerpo normativo, habría de aplicarse tal criterio o regla. Por ello el art. 13 lo acoge como regla, por la certidumbre de su aplicación en estos casos.

En cambio, en lo referido a cuerpos normativos distintos, el criterio de especialidad no es tema dentro del art. 13, y su aplicación dependería de cómo ha de relacionarse la considerada disposición normativa especial y la general, y sus relaciones con los demás criterios.

\section{c) Observaciones}

Las consecuencias que del análisis de la especialidad pueden inferirse, se resumen en lo siguiente:

- No es la existencia de una disposición o ley especial la que determina la especialidad, sino la forma de relación que se produce entre dos disposiciones o leyes, y que el intérprete es capaz de determinar en dicho sentido.

- Nunca la existencia de una disposición o ley normativa especial va a suponer a priori y necesariamente la aplicación de la especialidad. Y nunca va a presuponer, tampoco, la existencia de alguna forma específica de relación entre disposiciones normativas o leyes. Por el contrario, la existencia de una disposición normativa o ley especial traerá consigo siempre una incógnita, que será despejada solo ante una interferencia normativa específica.

\section{La supuesta especialidad consagrada en el art. $4^{\circ}$ del Código Civil}

El art. $4^{\circ}$ del Código Civil señala: "Las disposiciones contenidas en los Códigos de Comercio, de Minería, del Ejército y Armada, y demás especiales, se aplicarán con preferencia a las de este Código".

La opinión casi unánime de la doctrina entiende que el art. $4^{\circ}$ mencionado contempla la especialidad ${ }^{29}$.

De ellos, expondremos la opinión de GuZMÁn BRITO, pero confrontándola a la Historia de la Ley.

En la referencia del Proyecto de Código Civil de 1853 en su art. 16 y en las modificaciones manuscritas, Bello señala como regla la aplicación preferente

especialidad a derechos constitucionales, prefiriendo el de ponderación (BARBERIS (1998), pp. 1-20, p. 16).

${ }^{29}$ Por todos, Claro (1978), p. 37; Barros (1931), p. 20; Borja (1901), p. 69; GuzmÁn (2007), pp. 152 y ss.; Alessandri et al. (1998), p. 51; Vodanovic (2001), p. 21; Otárola (2012), en especial p. 93; Orellana (2000), pp. 817 y ss.; Ruz (2011), p. 133; VerGara (2010), pp. 31 y ss. 
o prioritaria ("se aplicarán con preferencia"; "se aplicarán sin perjuicio") de las disposiciones "especiales" ("y demás especiales") de los Códigos ${ }^{30}{ }^{31}$. La Comisión Revisora, en el art. $4^{\circ}$ del Proyecto Inédito, añadía al final la frase "en lo que tuviere de opuesto a ella", en un tenor similar al que aparece en el Proyecto de Código Civil español de 1851 o el Proyecto de García Goyena en su art. $17^{32}$ (que luego se suprime en el texto definitivo), lo que indicaba que la idea inicial de Bello no era la oposición como requisito para regular este caso de disposiciones especiales, sino solo la primacía de la disposición especial por la general.

Guzmán Brito reconoce la ausencia de dicha referencia, sin la cual, concluye, la disposición es incompleta o insuficiente. "El lector -señala el autor referido-, sólo con buena disposición y a la luz del modelo, puede concebir que el precepto manifieste los principios de especialidad y de subsidiariedad (...) Queda confiado al intérprete entender que la norma, en realidad, quiere estatuir sobre figuras interesantes (...) (principio de especialidad) (...) (principio de subsidiariedad)" ${ }^{\prime 33}$ [el resaltado es nuestro].

Lo que queda claro respecto de lo que señala el autor, es que el art. $4^{\circ}$ no dice absolutamente nada relativo a la aplicación de la especialidad en esta situación, sino que es el intérprete quien infiere aquello.

Fuera de esto, además indica: "Con ello [la supresión de la frase "en lo que tuviere de opuesto a ella"], aparentemente se dio un paso atrás, porque quedó omitido el supuesto principal que hace aplicable la ley especial por sobre la general, precisamente consistente en la oposición habida entre ambas" ${ }^{\prime \prime 4}$ [el resaltado es nuestro].

El autor expresamente señala que la oposición es lo principal -y nosotros diríamos esencial- para entender y aplicar la especialidad.

Sin embargo, agrega el autor:

"Con todo, la supresión no fue grave, porque, además de ser tan sólo el principal, mas no el único supuesto, ya que es suficiente haber diferencia de regulación y no necesariamente oposición, tal supuesto puede dejarse como elemento tácitamente operante, siempre que se establezca la preferente aplicabilidad de la norma especial, como de hecho se hace (...) En otras palabras, al disponerse que la ley especial prefiere a la general, se da por supuesto que ésta regula la materia en forma diferente (no necesariamente opuesta) a como la regula la general, y

\footnotetext{
${ }^{30}$ Pese a las referencias sobre la futura promulgación de Códigos que aún no habrían de dictarse, es de aplicación general, por su ubicación en este título preliminar y no en las disposiciones transitorias.

${ }^{31}$ Bello (1981), p. 29.

32 GuZMán (2007), pp. 150-153.

${ }^{33}$ GuZmán (2007), p. 152.

${ }^{34}$ GuZMÁN (2007), pp. 153-154.
} 
tal aplicación preferente tendrá lugar aunque no se declare expresamente tal supuesto. Como antes se observó, si no hay diferencias de regulación, lo más probable es que no haya norma especial, porque sería redundante o superflua" [el resaltado es nuestro] ${ }^{35}$.

¿Cómo es esto? Antes había dicho que era un supuesto principal, y luego señala que no es necesario. Después dice que puede comprenderse como un elemento tácito. Se está de acuerdo en que es tácito de algún modo, ya que la lógica jurídica lleva a concluir que en la especialidad la oposición no hace falta señalarla, pero en los hechos, en la praxis, al interpretar normas generales y especiales. Distinto es el caso de lo que señala el art. $4^{\circ}$ del Código Civil donde, según el principio de legalidad (que por lo demás es un principio liberal bajo cuya luz se origina este Código) no podemos suponer un elemento tácito, menos cuando de la semanticidad del mismo artículo no se subentiende la especialidad, la lex specialis derogat legi generali como regla. El art. $4^{\circ}$ no lo dice, y el entender que éste expresa la especialidad, criterio o principio de especialidad, es erróneo.

Si no expresa la especialidad, ¿entonces qué expresa?

Lo que de su tenor literal es posible colegir es solo lo que describe el Código Civil: "preferencia".

El diccionario de la RAE entiende por preferencia "primacía, ventaja o mayoría que alguien o algo tiene sobre otra persona o cosa, ya en el valor, ya en el merecimiento / elección de alguien o algo entre varias personas o cosas".

El art. $4^{\circ}$ señala la preferencia de disposiciones de cuerpos normativos especiales, y no alude a disposiciones especiales en otros cuerpos normativos distintos al Código Civil. Tampoco los efectos interpretativos son tan amplios como para entender que el art. $4^{\circ}$ haya de referirse a todo cuerpo normativo estimado como general, sino que su referencia solo es al Código Civil. Esto ya aparta una parcela de significación: que la referencia no es a todo cuerpo normativo, sino a la relación entre cuerpos normativos especiales y el Código Civil.

Es así como esta particular "preferencia" ocurrirá, según el art. $4^{\circ}$, del modo siguiente:

- Si, y solo si se trata de las disposiciones de una Ley especial.

- Si, y solo si la ley postergada, es el Código Civil.

Por otra parte, la preferencia del art. $4^{\circ}$ se refiere a un caso concreto, esto es, a las "leyes especiales" en relación al Código Civil. Y para abundar, se señalan de modo expreso qué cuerpos preferirán al Código Civil, y no ejemplificativamente, con lo cual la expresión "demás leyes especiales" es extensión de la preferencia que ordena el art. $4^{\circ}$ respecto de Leyes (Códigos) determinadas. La elección que implica la preferencia para este caso es normativa, porque -y en

35 GuZmán (2007), p. 154, incluyendo nota al pie № 347. 
el razonamiento de Von Wright ${ }^{36}$ - es relativo a la norma quién predetermina la elección ${ }^{37}$, o para ser más concretos, el legislador.

Esto no es propio de la especialidad, donde si bien existe una preferencia, ésta no está predeterminada como en el caso del art. $4^{\circ}$, sino que ella ha de aplicarse por el intérprete, y en la medida que su interpretación restrictiva (a la disposición que restringe el ámbito de aplicación) señale una antinomia o inconsistencia y los binomios normativos en contraposición. El art. 13 contempla estos supuestos, no así el art. $4^{\circ}$.

Por lo demás, ante la preferencia de otros cuerpos normativos por sobre el Código Civil, no implica que este último quede por efecto excluido, puesto que generalmente los cuerpos normativos especiales contienen, o disposiciones que ordenan la supletoriedad en remisión al Código Civili ${ }^{38}$, o bien remisión a disposiciones normativas de este último ${ }^{39}$, con lo cual se contradice el efecto lex specialis derogat legi generali. Las diferencias en este punto, son ostensibles entre el art. $4^{\circ}$ y el $13^{40}$.

36 "Toda preferencia, cualquiera que sea su tipo, es necesariamente relativa a un sujeto. Toda preferencia es siempre la preferencia de alguien. Sin embargo, hablando en general de un sujeto que no se especifica, puede ser conveniente recurrir a giros verbales impersonales: 'se prefiere', en lugar de la forma persona, 'fulano prefiere'” (VON WRIGHT (1967), p. 15). Y en efecto, para este caso, el sujeto que no se especifica es la ley en cuanto voluntad normativa.

37 "También se relaciona [la preferencia] con la noción de elección" (VON WRIGHT (1967), p. 16). Esto sería para el caso, elección de la voluntad normativa.

${ }^{38}$ Como es del caso del Código de Comercio el cual en su art. $2^{\circ}$ señala: "En los casos que no estén especialmente resueltos por este Código, se aplicarán las disposiciones del Código Civil".

${ }^{39}$ El Código de Minería hace aplicable el art. 651 del Código Civil, en su art. 13 inciso 2: "Las salinas artificiales formadas en las riberas del mar, lagunas o lagos, tampoco se consideran sustancias minerales, y el derecho a explotarlas corresponde a los propietarios riberanos dentro de sus respectivas líneas de demarcación, prolongadas directamente hasta el agua, debiendo aplicarse para este efecto las reglas que establece el artículo 651 del Código Civil". O al hacer aplicación del art. 150 del Código Civil en su art. 25: "Los derechos adquiridos en virtud del artículo anterior por los menores adultos quedarán incorporados a su peculio industrial. Los adquiridos por las mujeres casadas en régimen de sociedad conyugal ingresarán al haber social, a menos que sea aplicable el artículo 150 del Código Civil"; o el art. 92 inciso $3^{\circ}$ y $5^{\circ}$ que hace aplicable el art. 688 y 698 respectivamente: "Asimismo se constituirán los otros derechos reales que recaigan sobre la concesión, y se efectuará su tradición, mediante la correspondiente inscripción. No obstante, la tradición del derecho de servidumbre se hará con arreglo a lo dispuesto en el artículo 698 del Código Civil (...) A la transmisión de la concesión y de los derechos emanados del pedimento y de la manifestación, le será aplicable lo dispuesto en el artículo 688 del Código Civil"; o el art. 178 que hace aplicable el 688: "A la transmisión de las acciones será aplicable lo dispuesto en el artículo 688 del Código Civil"; o el art. 221 que hace aplicable el 2427: "La hipoteca sobre concesión no da al acreedor los derechos que otorga el artículo 2.427 del Código Civil, salvo que el deterioro o la pérdida se produzca por dolo o culpa grave del deudor".

${ }^{40}$ Señala VON WRIGHT lo siguiente: "Las propiedades formales de la relación de preferencia son la asimetría y la transitividad. Por asimetría debe entenderse que si un estado de cosas es preferido 
Siendo así, la palabra "preferencia" dentro del contexto del Código Civil, no está dispuesta en el texto para comprender la especialidad, regla, criterio o principio de especialidad. Lo que menciona el art. $4^{\circ}$ son disposiciones de leyes especiales en relación al Código Civil, pero el señalar piezas legales especiales no necesariamente conduce a la especialidad, a menos de existir oposición, y ni aún en estos casos, como se verá más adelante.

\section{Diferencias conceptuales tanto del art. 13 como del art. $4^{\circ}$ del Código Civil}

Si se expresa todo lo dicho de modo abreviado, se puede decir que ante leyes o disposiciones especiales, el Código Civil establece dos formas de regulación:

- La especialidad (ley especial deroga la general), cuando existe oposición entre disposiciones generales y especiales dentro de una misma Ley (art. 13).

- La preferencia de las disposiciones de una ley especial frente al Código Civil (art. $4^{\circ}$ ).

La especialidad (regla, criterio o principio) descrita por el Código Civil en el art. 13 se relaciona, según las anotaciones de Bello, a la regla lex specialis derogat legi generali, y al reconocer además la oposición entre disposiciones especiales y generales, no puede más que producirse para la disposición que cede ante la otra, la "derogación" para el caso en oposición, que no es más que el fenómeno que Bobbio señala como la pérdida parcial de vigencia, o también Ilamada "abrogación simple o interpretación abrogante" ${ }^{\prime 41}$. Pero al señalar la regla el término "derogación", supone que en el caso en específico donde colisiona la disposición general con la especial, la general se excluye totalmente, con lo cual es cancelada.

Por lo demás, queda cancelada o se produce su cancelación, justamente porque existe la oposición entre ambas disposiciones o cuerpos normativos. La

a otro, entonces y necesariamente el segundo estado no es preferido al primero; claro está, por el mismo sujeto y en la misma ocasión" (VON WRIGHT, La lógica de la preferencia, p. 26). Lo idéntico en los supuestos del art. $4^{\circ}$ y 13 , es que existe una preferencia de algo, y un desplazamiento de otro que iba en concurrencia a esa preferencia. En lo que difiere es el efecto jurídico en uno y otro caso: en el art. $4^{\circ}$ la preferencia no desplaza siempre al Código Civil; en cambio en el art. 13 se dispone una preferencia excluyente. Dicho en términos de lógica de las conectivas, mientras el art. 13 presenta un problema clásico de disyunción exclusiva. En este caso, la lógica es bivalente y la consecuencia es que la disyunción exclusiva nos conduce a una de las reglas de la lógica formal aristotélica, esto es, el de tercero excluso, ya que la ley especial escogida, excluye la aplicación de la ley general y en conjunto a aquélla, con lo cual tertium non datur. El art. $4^{\circ}$, en cambio, no implica una exclusión per se, donde el Código Civil excluido en primera instancia, pueda ser incluido dependiendo de que la probabilidad normativa determine su aplicación inclusiva. En este caso, tal vez se acomode más a una lógica trivalente, donde la inclusión del Código no sea ni verdadero (1) o falso (0), sino posible o incierto (1/2). Ver ŁUKASIEWICZ (1970).

${ }^{41}$ García-Berrio (1995), p. 190. Aunque en estricto rigor, es más bien una abrogación ficta. 
oposición como concepto siempre supondrá o su mantención (tensión dialéctica) o su resolución, lo que ocurre cuando uno de los términos en oposición supera al otro quien se ve excluido definitivamente (lógica formal, principio del tercero excluso), o bien ocurre su síntesis, como un tercer término quien excluye a los términos en disputa con su superación definitiva (dialéctica, sobre todo en Hegel). Para este caso en estudio, la exclusión es básicamente la consecuencia en lógica formal.

Lo dicho podemos expresarlo del siguiente modo.

El efecto que sucede entre la disposición "general" y la "especial", en cuanto ésta prima sobre aquélla, es la producción de una disyuntiva que lógicamente habría de resolverse con la exclusión de uno de los dos elementos en disyunción exclusiva (por ello la denominación de derogación). Dicho de otro modo, si siendo $p$ una disposición "general" y $q$ una disposición "especial", la tabla de verdad rezaría lo que sigue:

\begin{tabular}{c|c|c}
$p$ & $Q$ & $J p q^{42}$ \\
\hline $\mathrm{V}$ & $\mathrm{V}$ & $\mathrm{F}$ \\
\hline $\mathrm{F}$ & $\mathrm{F}$ & $\mathrm{F}$ \\
\hline $\mathrm{V}$ & $\mathrm{F}$ & $\mathrm{V}$ \\
\hline $\mathrm{F}$ & $\mathrm{V}$ & $\mathrm{V}$
\end{tabular}

En cambio el art. $4^{\circ}$ se refiere a otras cuestiones.

$\mathrm{El}$ art. $4^{\circ}$ regula la relación entre las disposiciones de una ley especial y el Código Civil, con lo cual el problema a resolver no es entre un cuerpo normativo especial y el Código Civil, sino entre éste y las disposiciones contenidas en dicho cuerpo normativo. Ello porque el art. $4^{\circ}$ considera a la Ley especial según sus materias, y por ello así las menciona ("Códigos de Comercio, de Minería, del Ejército y Armada, y demás especiales"), con lo cual los considera "especiales" por la regulación sectorizada o por la especificidad de la materia que regula.

El que diga lo obvio y evidente, como señala Guzmán Brito, esto es "que el Código Civil se aplica a sus casos, y que los códigos especiales se aplican a los suyos sin obstrucción de aquél"43, quiere significar además otra cosa, y es que los códigos se aplican a sus casos porque son especiales, lo que redunda

\footnotetext{
${ }^{42}$ En esta parte se usará la notación polaca.

${ }^{43}$ Guzmán (2007), p. 152.
} 
en que el significado de "especial" del art. $4^{\circ}$ es regulación según la materia: si la materia de la que se trata es "especial", la ley es especial. Ley especial así, es sinónimo de ley especializada. Así, el concepto de "especial" del art. 4, es diverso al del art. 13 del Código Civil.

De ahí que este concepto explique el por qué su regulación compromete solo al Código Civil, y no es una disposición general a todo cuerpo normativo, porque justamente lo que se quiere es prescribir la preeminencia de los cuerpos normativos especializados por sobre el Código Civil en particular, al regular sus propias materias. Para lo dicho, nos afirmamos en un fundamento histórico.

Las notas manuscritas de Bello señalaban para este artículo que "Las disposiciones contenidas en los Códigos de Comercio, de Minería, del Ejército y Armada, y demás especiales que se están redactando por disposición del Supremo Gobierno, se aplicarán con preferencia a las de este Código, desde que hayan sido promulgados", y el Proyecto de 1853 consignaba "y demás especiales que en adelante se promulguen" (art. 16). Tanto la nota de Bello como el art. 16 del Proyecto de 1853 regulan un problema específico, en un contexto en que pululaban una serie de leyes del derecho indiano, en un "estado caótico e irracional de los viejos cuerpos de legislación" ${ }^{44}$ y donde su aplicación se veía entenebrecida por las distintas fuentes existentes y sin solución en cuáles habrían de aplicarse en preferencia y cuáles secundariamente ${ }^{45-46}$. No es extraño, entonces, que la nota de Bello como el Proyecto aludido, hayan hecho mención de los Códigos y leyes especiales que no existían y que habrían de ser dictados, porque lo que se estaba regulando con el art. $4^{\circ}$ era la relación que habría de tener el Código Civil con otros Códigos que abordaban otras materias y sus parcelas de acción. Es decir, cómo leyes dictadas en tiempos distintos irían a operar entre sí, una vez dictadas. La idea era establecer un principio de orden, de sistematización, ante el panorama asistemático y desordenado de la legislación del tiempo ${ }^{47}$.

\footnotetext{
${ }^{44}$ GuZmán (1979), p. 323.

${ }^{45}$ Ver Bravo (1984), pp. 5-52.

${ }^{46}$ En Chile al tiempo de la Constitución de 1818, ésta decía: "Integridad, amor a la justicia, desinterés, literatura y prudencia deben ser las cualidades características de los miembros del Poder judicial, quienes ínterin se verifica la reunión del Congreso, juzgarán todas las causas por las leyes, cédulas y pragmáticas que hasta aquí han regido, a excepción de las que pugnan con el actual sistema liberal de gobierno. En este caso consultarán con el Senado, que proveerá de remedio" (art. 2, cap. I, título V, Constitución provisoria del Estado de Chile de 1818). Ello habría de significar la ausencia de criterios de aplicación de una legislación de fuentes distintas (derecho castellano, romano, canónico; leyes patrias).

${ }^{47} \mathrm{Al}$ igual que lo que había ocurrido para la dictación del Código Civil "napoleónico" en Francia, y que fue inspiración del Código Civil chileno. Ver CabriLlac (2009), pp. 65-73, en especial p. 66.
} 
TARRASA, en un antiguo libro civilista, expresa muy bien el término de "especial", como sinónimo de ley especializada. En comentario al Proyecto de Código Civil español de la época que contemplaba en su art. 17 (muy similar al art. $4^{\circ}$ del Código Civil chileno), "Las disposiciones de este Código sólo son aplicables á los asuntos que se rijan por las leyes de comercio, minas y otras especiales, en cuanto no se opongan á estas leyes", el autor expresa lo siguiente:

"si en mucha [sic] de las instituciones de derecho civil encontramos siempre una de esas circunstancias particulares que hacen necesaria la aplicación de una ley diferente, es sólo una cuestión de método el separar todas esas circunstancias excepcionales y formar de ellas una legislación especial, tal es la Legislación de Comercio (...) Esto hace que, reconocida tal profesión por la ley [la de Comercio] y probada su importancia, á [sic] los actos en que por ambas partes ó por una tan solo existe una operación mercantil, la ley les encuentra una circunstancia digna de especialidad en sus disposiciones, y da lugar á [sic] una série [sic] de disposiciones excepcionales que constituyen ramo aparte en el árbol de la legislación. Hé [sic] aquí pues, como se forman las legislaciones especiales, sin ser una contradicción de la general..." [el resaltado es nuestro ${ }^{48}$.

En primer lugar, no existen disposiciones en disputa, sino que comprende una regla general, que es la de estimar las disposiciones de cualquier cuerpo normativo especial con preeminencia respecto al Código Civil. Este último no queda desplazado absolutamente, es decir, no queda excluido o cancelado, porque no existe oposición.

En segundo lugar, el Código Civil no queda excluido en su aplicación, ya que si existen las disposiciones de los cuerpos normativos especiales en preferencia, implica que cuando éstos pierden la preferencia, ante quien está en segundo lugar (Código Civil), será éste quien retome la posición desplazada. De algún modo, esta preferencia es un desplazamiento condicional, y la condición dependerá de si pierden esa preferencia las disposiciones del cuerpo normativo especial o no, ya que si pierden dicha preferencia, quien asume el lugar dejado por la disposición o cuerpo normativo preferido, es el Código Civil.

Este concepto es el que aparece en algunas otras de las disposiciones del Código Civil, como el art. 611: "La caza marítima y la pesca se regularán por las disposiciones de este Código y, preferentemente, por la legislación especial que rija al efecto".

Dos legislaciones concurren a regular el mismo objeto: el Código Civil y la legislación especial. Sin embargo, no existe exclusión del Código Civil, más

48 TARRASA (1866), p. 190. 
aún, el mismo artículo se encarga de señalar que aquél no queda excluido ("se regularán por las disposiciones de este Código"), pero la preferencia la tiene la legislación especial. Si la preferencia la tiene la legislación especial, y no obstante ello, igual se menciona que se regirán por las disposiciones del Código Civil, nos da a entender que fuera de su exclusión, éste se incluye y concurre, respecto del art. 611, supletoriamente.

Son, entonces, leyes especiales, pero su forma de regulación es diferente a la especialidad donde la disposición concurrente queda excluida.

En resumen, lo que se sostiene es lo siguiente:

- La especialidad del art. 13 solo puede operar entre disposiciones de una ley, no respecto de un cuerpo normativo completo. La preferencia del art. $4^{\circ}$ opera por regla general, entre cuerpos normativos, y no entre disposiciones de una ley.

- La especialidad del art. 13 opera ante la inconsistencia total-parcial o ante la "antinomia normativa" -como las Ilama Bobbio ${ }^{49}$ - o "antinomia real" o "de segundo grado" ${ }^{50}$ de las disposiciones de una ley, o bien, ante una redundancia aparente entre disposiciones de una ley.

Por ello lo señalado por GUASTINI se puede traer a colación con mayor razón, en el sentido de que en disposiciones de documentos normativos distintos, el criterio de especialidad solo podría determinar si una de las dos normas es ineficaz, pero en interferencia y en conjunción con los criterios cronológico o jerárquico ${ }^{51}$, ya que en esta situación no opera la regla de que la norma especial deroga a la general, menos si se trata de cuerpos normativos completos.

Por ello es que pensamos que el art. $4^{\circ}$ no pudo ir en esa vía, ya que si se sostuviese que este aplica la especialidad entre cuerpos normativos distintos (leyes), se estaría presumiendo de derecho que la Ley "especial", en el sentido de especializada, prima con efectos derogatorios y de eficacia sobre la Ley general, cual sería ante esta situación ineficaz. Pero el art. $4^{\circ}$ no dice eso, sino solo la preferencia, con lo que no podría contener la especialidad.

Por otra parte, la doctrina civil en general hace la distinción de que una cosa es el cuerpo normativo y otra una disposición en particular, y sobre cómo existiendo un cuerpo normativo especial, este puede contener disposiciones normativas de carácter general o común. Sin embargo, no obstante reconocer este hecho y al analizar el concepto de especial, confunde las disposiciones del art. $4^{\circ}$, entendiendo que éste habla de la misma especialidad que el art. 13,

\footnotetext{
${ }^{49}$ Bоввіо (1987), pp. 184 y ss.

${ }^{50}$ García-Berrio (1995), p. 189.

${ }^{51}$ GuASTINI (1999), pp. 442-443.
} 
cuando es claro que el primero se refiere a cuerpos normativos, y este último a disposiciones, con lo cual no se sigue la misma lógica de razonamiento.

Es así como Alessandri; Somarriva; Vodanovic señalan:

"Por diversas causas una norma de derecho común suele colocarse en un cuerpo legal de normas especiales. A nuestro juicio, dicha norma mantiene su carácter general, porque el carácter de las normas lo da su propia naturaleza y no el conjunto en que se hallan. Por eso si una norma general o de derecho común se encuentra en un Código especial, debe aplicarse en materias que son de derecho común" ${ }^{\prime \prime 2}$.

Esto significa que los autores hacen la diferenciación correcta entre disposiciones y cuerpo normativo, al enfrentar la especialidad, pero no siguen esta misma lógica al enfrentar el art. $4^{\circ}$ respecto del art. 13, confundiéndolos al señalar que ambos se refieren a la especialidad, no obstante que el primero se refiere a cuerpos normativos, y el último a disposiciones normativas.

Igualmente, VoDANOVIC entiende bien el concepto de especialidad al decir:

"Por último, la calificación de si una norma es de derecho común, general o de derecho especial depende de su propia naturaleza y no del cuerpo legal en que está. Una norma general puede, por cualquier razón, estar colocada en un cuerpo de normas legales especiales y no por eso deja de ser general. Es como si en un estante de libros dedicados a contener los que versan sobre historia de Chile, colocáramos por falta de espacio en otro un libro de historia universal; obvio es que por la circunstancia de su ubicación no se convierte en un tomo de historia de Chile" ${ }^{\prime 53}$.

Sin embargo, en párrafos anteriores a esta declaración confunde lo señalado por el art. $4^{\circ}$ y lo designa como especialidad del mismo modo que el art. 13, no obstante que luego y como aparece en el texto extractado, señala cómo la especialidad se refiere solo a disposiciones y no a cuerpos normativos, y cómo cuerpos normativos de aquellos Ilamados "especiales" pueden contener normas comunes.

\section{Conclusión}

Conforme al proceso de desambiguación que hemos desarrollado, es posible detallar algunas conclusiones del ejercicio antedicho.

\footnotetext{
${ }^{52}$ AlesSandri et al. (1998), p. 51.

53 VODANOVIC (2001), p. 21.
} 
El concepto de "especial" en el Código Civil, es polisémico ${ }^{54}$, porque contempla dos significados. Es así como el art. $4^{\circ}$ consigna un concepto diferente del art. 13 para el término especial, entendiéndolo más bien como sinónimo de especialización, ya que su referencia es a cuerpos normativos, en tanto éstos regulan de modo acotado un área determinada del Derecho, y que como especializados aquellos cuerpos normativos que señala el Código Civil en el art. $4^{\circ}$ y en razón de dicha especialización, prevalecerán y serán preferidos al Código Civil. Así, la expresión "demás especiales" tendría como significado 'legislación especial', es decir, una legislación que reclama una parcela de regulación diferente de otras, y que por su diferencia, hace necesaria una legislación más detallada, entendiendo así su regulación desde su complejidad.

Siendo así, el primer concepto (especialidad) está orientado hacia los problemas de (in)consistencia o antinomia normativa, en cambio el segundo (especialización) como sinónimo de ocupación, competencia, particularidad, dedicación, materia, rama.

Al tratar de equiparar el art. $4^{\circ}$ a la especialidad del art. 13 , se termina entrando en una ambigüedad del concepto de especialidad, confundiéndolo con el concepto de especialización, y en último término con el de supletoriedad ${ }^{55}$.

Por ello se hace necesario establecer la diferenciación de conceptos usados, tanto por el art. $4^{\circ}$, como por el art. 13, para evitar confusiones y ambigüedades semánticas.

${ }^{54}$ VerGara considera el término "norma especial" como polisémico y ambivalente. VerGara (2010), p. 57.

${ }^{55}$ En efecto, BorJA, cuando habla de la especialidad, confunde de modo importante los institutos señalados en el cuerpo del texto. Es así como expresa lo siguiente: "La razón se presenta á primera vista. Cuando el legislador dicta leyes generales, atiende á una materia; mientras que al expedir leyes especiales se fija, por decirlo así, en individuos determinados, á quienes excepciona de la regla á [sic] virtud de circunstancias peculiares (...) compele al juez á [sic] fijarse con suma frecuencia en las leyes peculiares á cada objeto determinado, y á [sic] no aplicar las leyes generales sino cuando aquéllas faltan. Análoga es la disposición del art. 13 á la del art. 4; porque exceptuándose el Código civil, todas las demás son leyes especiales" (BorJA (1901), pp. 192-193). La relación entre especialidad con individuos determinados (no obstante que en los ejemplos anteriores que señala en su libro hace alusión a individuos, pero la afirmación en cuestión carece de generalidad), ya es complicada, porque no es a individuos determinados la aplicación de la especialidad, sino más bien a supuestos respecto de los cuales una disposición normativa ha de referirse. Aún menos se puede referir a individuos a quienes excepciona la ley de la regla por sus circunstancias peculiares, porque ya estamos entrando en el terreno de la especialización, y comienza a confundirse sus presupuestos. El hecho de señalar "no aplicar las leyes generales sino cuando aquéllas faltan", esta aludiendo más bien a la supletoriedad, y no a la especialidad. Al expresar el autor que "Análoga es la disposición del art. 13 á la del art. $4^{\circ}$; porque exceptuándose el Código civil, todas las demás son leyes especiales", tal equiparación es confundir nuevamente, lo que señala el art. $4^{\circ}$ con la especialidad, o el art. $4^{\circ}$ con el art. $13^{\circ}$, o los efectos del art. $13^{\circ}$ con aquellos del art. $4^{\circ}$. 


\section{BibliOgRAFíA CitADA}

Alessandri, Arturo; Somarriva, Manuel; Vodanovic, Antonio (1998): Tratado de Derecho civil, Partes Preliminar y General (Santiago, Editorial Jurídica de Chile), tomo I.

Baró Pazos, Juan (1993): La codificación del derecho civil en España: (18081889) (Santander, Ediciones Universidad de Cantabria).

Barros Errázuriz, Alfredo (1931): Curso de Derecho Civil, $4^{a}$ edición (Santiago de Chile, Editorial Nascimento), Vol. 1.

Bello, Andrés (1981); Obras Completas de Andrés Bello, 2ª edición (Dir. Rafael Caldera, Caracas, Fundación La Casa de Bello), tomo XIV.

Bıond, Biondo (1951): II dirito romano cristiano (Milano, Giuffrè), Vol. II.

Bоввіо, Norberto (1987): Teoría general del Derecho (Bogotá, Temis).

Borja, Luis F. (1901): Estudios sobre el Código Civil Chileno (Paris, A. Roger y F. Chernoviz), Tomo I.

Bravo LiRA, Bernardino (1984): "El derecho indiano después de la independencia en América española, Legislación y doctrina jurídica", en: Historia, (№ 19), pp. 5-52.

Cabrillac, Rémy (2009): "El derecho civil francés desde el Código Civil", en: Revista de Derecho Universidad Austral de Valdivia (Vol. XXII, $N^{\circ} 2$ ), pp. 65-73.

Claro Solar, Luis (1978): Explicaciones de derecho civil chileno y comparado, Vol. I, De las Personas (Santiago de Chile, Editorial Jurídica de Chile).

FERRAJOLI, Luigi (2006): "La teoría del derecho en el sistema de los saberes jurídicos", en: Las garantías de los derechos fundamentales. Garantismo y teoría del derecho, Seminario de Derecho y Jurisprudencia, $3^{\circ}$ Jornada (Madrid, Fundación Coloquio Jurídico Europeo). Disponible en: http://www.fcje.org.es/wp-content/ uploads/file/jornada3/1_FERRAJOLI(1).pdf [visitado el 06/07/2013].

García-Berrio, Ma Teresa (2005): "Decálogo de las principales aportaciones de Norberto Bobbio al tratamiento de las antinomias", en: Analisi e diritto, (sin volumen), pp. 183-191. Disponible en: http://www.giuri.unige.it/intro/dipist/ digita/filo/testi/analisi_2006/14garciaberrio.pdf [visitado el 05/07/2013].

GuastinI, Riccardo (1999): "Antinomias y lagunas" (traducc. Miguel Carbonell), en: Jurídica. Anuario del departamento de derecho de la Universidad Iberoamericana (Número 29), pp. 437-450.

GuZMÁn BRITO, Alejandro (1979): "Para la historia de la fijación del derecho civil en Chile durante la República", en: Historia ( $\left.N^{\circ} 14\right)$.

Guzmán Brito, Alejandro (2007): Las reglas del "Código Civil" de Chile sobre interpretación de las leyes (Santiago de Chile, LexisNexis). 
Josserand, Louis (1952): Derecho Civil [Santiago Cunchillos y Manterola], Volumen 1, Teorías Generales del Derecho y de los derechos de las personas (Buenos Aires, Bosch), tomo I.

KANTOROWICZ, Hermann (1949): "La lucha por la Ciencia del Derecho", en: Savigny; Kirchmann; Zitelmann; Kantarowicz, La Ciencia del Derecho (Buenos Aires, Editorial Losada), pp. 325-373.

LASTRA LASTRA, José Manuel (2003): "Derecho a la lengua y lenguaje jurídico", en: J. E. R. Ordóñez Cifuentes (coord.), El derecho a la lengua de los pueblos (México D.F., UNAM), pp. 1-16. Disponible en: http://biblio.juridicas.unam. mx/libros/2/740/5.pdf [visitado el 05/08/2013].

ŁUKASIEWICZ, Jan (1970): Estudios de lógica y filosofía (Madrid Revista de Occidente).

MarinelLI, Vincenzo (1998): "Il problema dell'ermeneutica giudiziaria", Analisi e diritto, en: Comanducci, P.; Guastini, R. (redattori) (Torino, G. Giappichelli Editore), pp. 145-158.

NıNO, Carlos Santiago (2003): Introducción al análisis del derecho, $2^{\circ}$ edición (Buenos Aires, Editorial Astrea).

Orellana Retamales, Luis (2000): "La supletoriedad de las leyes", en: Revista Chilena de Derecho, Sección Estudios (Vol. 27, № 4), pp. 807-822.

OtÁrola, Yasna (2012): "La función supletoria de las normas de derecho Civil", en: Revista Chilena de Derecho y Ciencia Política (Vol. 3, № 2), pp. 89-108.

PINO, Giorgio (1998): "Coerenza e verità nell'argomentazione giuridica. Alcune riflessioni", en: Rivista Internazionale di Filosofia del Diritto ( $\left.\mathrm{N}^{\circ} 1\right)$, pp. 84126.

PINO, Giorgio (2012): "Norma giuridica", in corso di pubblicazione en: AA.VV., Filosofia del diritto. Introduzione critica al pensiero giuridico e al diritto positivo (Torino), pp. 1-34. Disponible en: http://www.unipa.it/ dpds/php/ images/villa/pino,\%20norma\%20giuridica.pdf [visitado el 29/07/2013].

RADBRUCH, Gustav (2005): Introducción a la Filosofía del Derecho, 9a edición (traducc. Wenceslao Roces, México D.F., Fondo de cultura económica).

Ross, Alf (1974): Sobre el derecho y la justicia, 3ª edición (traducc. Genaro R. Carrió, Buenos Aires, Editorial Universitaria de Buenos Aires).

Ruz Lártıga, Gonzalo (2011): Explicaciones de derecho civil. Parte General y acto jurídico (Santiago de Chile, Legal Publishing), tomo I.

TARRASA, Manuel B. (1866): Estudios de derecho civil de España, comparado con el romano y el estranjero, segun el órden del proyecto de código civil español, Estudios Primero, Título Preliminar de las Leyes, Volumen 1, (Salamanca, Imprenta de la Casa-Hospicio). 
Van Rhee, C.H. Remco (2011): "Tradiciones europeas en el procedimiento civil: una introducción", en: Revista de Estudios de la Justicia ( ${ }^{\circ}{ }^{15}$ ), pp.19-20.

Vergara Blanco, Alejandro (2010): El Derecho Administrativo como sistema autónomo. El mito del Código Civil como "Derecho Común", Colección Ensayos jurídicos (Santiago de Chile, Abeledo Perrot Legal Publishing).

VISSER, Pepijn R.S.; BENCH-CAPON, Trevor J.M. (1998): "A comparison of four ontologies for the design of legal knowledge systems" en: Artificial Intelligence and Law (6, $N^{\circ} 1$ ), pp. 27-57. Disponible en: http://citeseerx.ist.psu.edu/ viewdoc/download?doi=10.1.1.54.1166\&rep=rep1\&type=pdf [visitado el 21/07/2013].

VodANOVIC, Antonio (2001): Manual de Derecho Civil, Partes Preliminar y General (Santiago, Editorial Jurídica Conosur).

VON WRIGHT, Georg (1967): La lógica de la preferencia (traducc. Roberto J. Vernengo, Buenos Aires, Editorial Universitaria de Buenos Aires).

Zorzetto, Silvia (2011), "Norme speciali e deroga Alcune precisazioni sul principio lex specialis derogat generali", en: Revus ( $\left.\mathrm{N}^{\circ} 15\right)$ Zakonoslovje. Disponible en: http://revus.revues.org/708 [visitado el 29/07/2013]. 